\title{
The Impact of Budget Reforms on the Quality of Budget Management in Nigeria
}

\author{
Ben-Caleb Egbide ${ }^{1}$, Adeyemi Kenneth Sola ${ }^{2}$ and Iyoha Francis ${ }^{3}$ \\ ${ }^{1,3}$ Department of Accounting School of Business, College of Development Studies \\ Covenant University, Ota Ogun State, Nigeria \\ ${ }^{2}$ Department of Business Management School of Business, College of Development Studies \\ Covenant University, Ota Ogun State, Nigeria
}

Correspondence should be addressed to: Ben-Caleb Egbide; egbide.bencaleb@covenantuniversity.edu.ng

Received date: 21 September 2013;Accepted date: 10 January 2014; Published date: 30 May 2014

Copyright (C) 2014. Ben-Caleb Egbide, Adeyemi Kenneth Sola and lyoha Francis. Distributed under Creative Commons CC-BY 3.0

\begin{abstract}
Budget management reforms were the major areas of the Nigerian public service reforms undertaken from the inception of civilian administration in 1999. The major objective was to enhance budget discipline among others. This was predicated on the theoretical considerations that improving the process and management of budgeting through reforms would be ultimately translated into improved budgetary outcome. This paper empirically investigated the impact of budget reforms on the quality of budget management in Nigeria. The Medium Term Expenditure Framework (MTEF) and the Fiscal Responsibility Act (FRA) form the proxies for budget reforms, while budget discipline (BDISC) and fiscal discipline (FDISC) were used as proxies for the quality of budgeting. Historical time series data representing 7years before and 7 years after the adoption of MTEF, and 5 years before and 5 years after the enactment of FRA were collected and analysed using the pre-test/post-test design of a Paired Sample T-test. The result favoured our initial proposition that budget reforms (MTEF and FRA) had not significantly impacted on the quality of budget management (BDISC and FDISC) in Nigeria. It was, therefore, recommended that the government should provide the leadership and political will, not only to enforce the provisions of FRA, MTEF and other reforms, but to sanction those that short circuit the system to their advantage. This will go a long way to enhance compliance with the reforms, and bring about the expected improvement in the quality of the nation's budget management.
\end{abstract}

Keywords: Budget, Reforms, Quality, Management

Cite this Article as: Ben-Caleb Egbide, Adeyemi Kenneth Sola and Iyoha Francis (2014), "The Impact of Budget Reforms on the Quality of Budget Management in Nigeria", Journal of Accounting and Auditing: Research \& Practice, Vol. 2014 (2014), Article ID 207739, DOI: 10.5171/2014.207739 


\section{Introduction}

The relevance of a budget in any economy cannot be overemphasized. The budget does not only function as a mechanism for resource mobilisation and allocation, it also serves as a tool for economic management (Olomola, 2009 and Government Integrated Financial Management Information System (GIFMIS), 2011). This is because the budget document sets the direction for the entire economy, determines who gets what and when, as well as provides funds to implement new initiatives/policies through legal, rational and acceptable means (Bengali, 2004). In fact, it will be very difficult if not impossible for the government in any modern economy to realise her vision in any fiscal year without the instrumentality of budgeting (Olomola, 2009). This is why, the development of a nation's budget is considered to be the government's single most important activity in any given year (Government Finance Officers Association (GFOA), 1999; National Democratic Institute (NDI), 2003).

However, for a budget to function as an instrument of fiscal cum macroeconomic engineering, both the budget process and budget management must be sound. By sound budgeting, we mean a well-planned and implemented public spending strategy that promotes technical efficiency, allocative efficiency and equity (Lucien, 2002). It is the budget process that is characterised by fiscal discipline and efficiencies in both operational and allocative dimensions (Olomola, 2006, Olomola, 2009). The lack of these basic ingredients of sound budgeting in most African countries, including Nigeria, has justified the description of their budgetary performances as disappointing, and underscores the need for reforms in public financial management in general and budget management in particular (Lienert \& Sarraf, 2001).

In Nigeria, budget management reforms were the major areas of the public service reforms undertaken from the inception of civilian administration in 1999. Prominent among these reforms were: the Medium Term Expenditure Framework (MTEF) introduced in 2005, and the Fiscal Responsibility Act (FRA) passed into the law in 2007. The objectives of these reforms were to improve resource management by curtailing wasteful spending, and to ensure budget discipline among others (Government Integrated Financial Management Information System, 2011). After seven (7) years of the adoption of MTEF and five (5) years of the enactment of FRA, the realisation of the reforms' objectives does not seem to be evident.

It is against this back drop that this study was conceptualised. The objective is to empirically investigate the impact of MTEF and FRA on the quality of budget management in Nigeria. The rest of the paper is organised into four sections namely: literature review and theoretical framework, the study methodology, data analysis and conclusion.

\section{Literature Review and Theoretical Framework}

\section{The Budgetary Reforms in Nigeria}

One of the major concerns of the government from the inception of the democratic civilian administration in 1999 was the rate of extra budgetary spending, and blatant disregard to budget rule perpetrated by previous (military) administrations (Ben-Caleb \& Agbude, 2013). Specifically, during the military regimes, the budget process was said to be thrown into disarray with major defects which precluded the budget from performing its role effectively as a tool for economic transformation, rather pressurised the nation into economic instability (Obasanjo, 1999). Expectedly, a number of reforms were embarked upon aimed at revamping the processes, programmes and policies considered ailing, in order to bring the economy on tract with the new democratic agenda and to delivering value to the people. The public sector in general and the public 
budget process in particular were among the areas for which reforms were exigent.

Consequently, a number of budget related reforms were introduced into the Nigeria budget process. These include; Oil-Price based on fiscal rule, the Medium Term Expenditure Framework (MTEF) 2005, and the Fiscal Responsibility Act 2007 among others (Garba, 2011). The reforms centred on five major aspects namely; administrative procedures, budget preparation, management of government spending, budget implementation, as well as budget monitoring and evaluation. They were intended to achieve the following objectives among others; reduce the cost of governance, improve the management of resources by curtailing extravagances, increasing the level of productivity and efficiency, as well as ensure budget discipline (i.e. adherence to limits) (Olomola, 2009; GIFMIS, 2011)

Specifically, the Medium Term Expenditure Framework (MTEF) was introduced into the Nigerian budgetary process in 2005; although it's legal backing came via the Fiscal Responsibility Act in 2007. According to Pascua (2005), MTEF entails annual budgeting system in which budget decisions relating to new programs and projects are made at every budget preparation session based on three-year fiscal scenarios, to ensure that projects financed for the next three years will be approved under the annual system and will be consistent with the baseline budgeting approach. Its emphasis is on a multi-year (three years) budget packaging. The specific objectives for the adoption of MTEF in Nigeria were to improve the allocation of resources to strategic priorities among and within sectors, as well as provide MDAs with a hard budget constraint among others (Olomola, 2009; State Partnership for Accountability, Responsiveness and Capability (SPARC), 2009).
Similarly, the Fiscal Responsibility Act (FRA) was signed into the law by President Musa Yar'Adua in 2007. It was meant to ensure prudent management of national resources, a mandate consistent with section 16 of the 1999 constitution, among others. Besides, the FRA was set to promote greater accountability and transparency in fiscal operations and processes within the medium term fiscal policy framework (Omolehinwa \& Naiyeju, 2011). In summary, the enactment of FRA formed the legal basis for the MTEF, and gave impetus to other budget reforms as well.

\section{The Relationship between Budget Reforms and Budget Management}

Budget reforms involve making changes to the ways and manner in which the budget is formulated, implemented and evaluated for the purpose of facilitating effectiveness, efficiency and economy (Allen 1998 cited in world Bank 2001). It is about restructuring the process and/or management of a nation's budgeting system in order to improve its feasibility as a fiscal policy vehicle. By implication, therefore, budget reforms must have direct impact on the quality of budget management, otherwise it would be unnecessary.

Supportably, the five planks of the reforms mentioned earlier in this paper (i.e. administrative, preparation, management, implementation and monitoring/evaluation) resonated with both, the four phases of the budget cycle (formulation, enactment, execution and evaluation), and the five major elements of budget management (efficiency, effectiveness, discipline, transparency and accountability). It is this interconnectedness that forms the fulcrum of the conceptual and theoretical underpinning of this study as depicted in figure 1. 


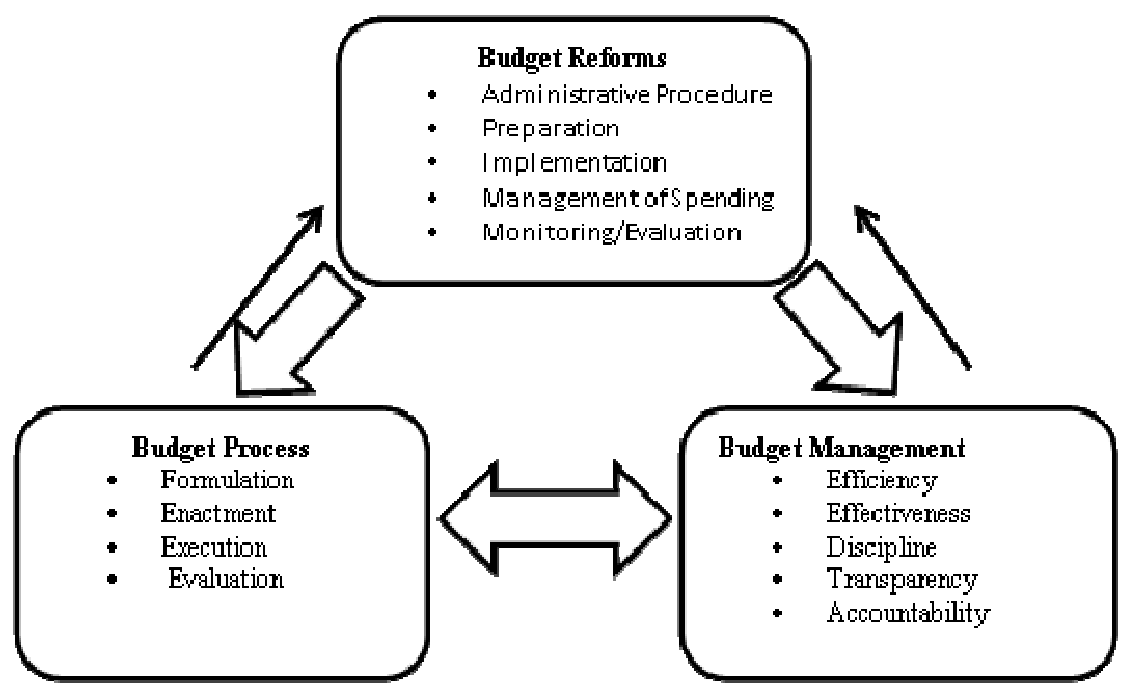

Figure 1: Budget Reforms, Budget Cycle and Budget Management Conceptual Relationship

Figure 1 demonstrates a relationship among the three budgets' constructs (Reforms, process and management). The thick arrows represent direct relationships or feedforwards, while the thin arrows represent feed-backs. The implication exemplified in the model is that budget reforms instigate changes in the process, as well as the management of the budget in order to improve its workability as an economic management tool. It is also in conformity with the theoretical postulates by institutional economists that institutional reforms are a necessary condition for achieving durable budgetary outcomes. Or that the "rule of the game" does shape the nature of decisions taken. Hence, changing the rule of the game can help in reducing the likelihood of systematic biases for poor budget/fiscal outturns (Brumby, 1998). This implies that appropriate and effective reforms of the institutions of budgetary process and management mean shaping the rules of the game which invariably have far reaching implications on the budgetary outturn.

However, most budgetary reforms are targeted at the implementation phase of the budgetary process, because of its susceptibility to corruption and misappropriation. This to a great extend explains why the specification of hard budget constraint or fiscal rules is a common factor of most reforms, hence, the concentration of this paper on budget/fiscal discipline. Conceptually, budget discipline is different from fiscal discipline in the sense that while budget discipline is measured by the ratio of budgetary expenditure to actual expenditure, fiscal discipline is measured by the ratio of budget deficit to the Gross Domestic Product. However, both are attributes of efficient fiscal policy management, hence, share similar implication on the economy (GDP).

In Nigeria, budget implementation failure had been attributed largely to budget/fiscal indiscipline associated with long years of military rule (Aruwa, 2004). It was this worrisome fiscal management that led to the inclusion of budget discipline improvement in the Obasanjo's public sector reform agenda. The question now is, have the reforms changed the trend of flagrant nonadherence to rules? An empirical answer to this question is the preoccupation of this paper. 


\section{Research Methods}

This paper adopted an analytical/explanatory research design to assess the impact of budget reforms on the quality of budget management in Nigeria. Analytical design was considered appropriate for this study since it entails the collection and analysis of quantitative data to explain the phenomenon of interest (Otokiti, 2010). The study focused on the Medium Term Expenditure Framework adopted in 2005, and the Fiscal Responsibility Act (FRA) enacted in 2007. MTEF was chosen because it forms the fulcrum for the preparation of the nation's annual budget since its adoption in 2005, while the Fiscal Responsibility Act (FRA) provides the legal backing for MTEF, as well as other reforms introduced into the Nigerian budgetary process.

The quality of budget management was proxied by budget discipline and fiscal discipline. Budget discipline was measured as the ratio of budgeted expenditure to actual expenditure. This is mathematically shown as; $\mathbf{B D I S C}=\frac{\mathbf{B E}}{\mathbf{A E}}$; Where BDISC is budget discipline, BE is budgeted amount, and AE is actual Expenditure. Discipline is achieved when BDISC $\geq 1$; but when BDISC \& 1 , it is indiscipline.

Fiscal discipline was measured as the ratio of budget deficit to GDP. It is mathematically presented as; $\mathbf{F D I S C}=\frac{\mathbf{B D}}{\mathbf{G D P}} ; \quad$ where
FDISC is fiscal discipline, BD is budget deficit (i.e. the amount of expenditure in excess of revenue), and GDP is Gross Domestic Product. Discipline is achieved when FDISC is positive $(t)$; but when FDISC is negative $(-)$ it is a demonstration of fiscal indiscipline.

The data for the study relating to the two variables (BDISC and FDISC) were extracted from CBN statistical Bulleting (2012), annual budgets and budget speeches for several years. It is worthy to mention that the figures for BDISC were computed by the authors, while the figures for FDISC were extracted directly from the CBN bulletin (2012). The data cover a period of 14 years (1998-2012) for MTEF excluding the year of intervention (2005), and 10 years (20022012) for FRA also excluding the year of intervention (2007). The Paired Sample Ttest (PST) (the pre-test/post-test design) was employed for the analyses with the aid of the Statistical Package for Social Sciences (SPSS).

\section{Data Presentation, Analysis and Discussion of Result}

The data used for this study were presented, analysed and discussed. The section also captures the testing of the only hypothesis of this study.

- Data Presentation

Table 1: Budgeted Expenditure, Actual Expenditure and Budget Discipline (1998-2012)

\begin{tabular}{|c|c|c|c|c|}
\hline Year & TBEXP & TAEXP & BDISC & FDISC \\
\hline $\mathbf{1 9 9 8}$ & 367917.1 & 487113.4 & 0.755301 & -4.92497 \\
\hline $\mathbf{1 9 9 9}$ & 358103.5 & 947690 & 0.37787 & -8.92622 \\
\hline $\mathbf{2 0 0 0}$ & 664733.3 & 701050.9 & 0.948195 & -2.26483 \\
\hline $\mathbf{2 0 0 1}$ & 1018026 & 1017997 & 1.000029 & -4.6782 \\
\hline $\mathbf{2 0 0 2}$ & 1188735 & 1018178 & 1.167511 & -4.36032 \\
\hline $\mathbf{2 0 0 3}$ & 1225957 & 1225988 & 0.999974 & -2.38864 \\
\hline $\mathbf{2 0 0 4}$ & 1302232 & 1461894 & 0.890784 & -1.51258 \\
\hline $\mathbf{2 0 0 5}$ & 1799938 & 1840700 & 0.977855 & -1.10763 \\
\hline
\end{tabular}

Ben-Caleb Egbide, Adeyemi Kenneth Sola and Iyoha Francis (2014), Journal of Accounting and Auditing: Research \& Practice, DOI: 10.5171/2014.207739 


\begin{tabular}{|c|c|c|c|c|}
\hline Year & TBEXP & TAEXP & BDISC & FDISC \\
\hline $\mathbf{2 0 0 6}$ & 1900010 & 1942488 & 0.978132 & -0.54619 \\
\hline $\mathbf{2 0 0 7}$ & 1940395 & 2348551 & 0.826209 & -0.56753 \\
\hline $\mathbf{2 0 0 8}$ & 2112723 & 3078252 & 0.686338 & -0.19501 \\
\hline $\mathbf{2 0 0 9}$ & 2445700 & 3280771 & 0.745465 & -3.26692 \\
\hline $\mathbf{2 0 1 0}$ & 3381000 & 3993249 & 0.846679 & -3.25264 \\
\hline $\mathbf{2 0 1 1}$ & 4226190 & 4233013 & 0.998388 & -3.09683 \\
\hline $\mathbf{2 0 1 2}$ & 4749000 & 4199978 & 1.13072 & -2.40657 \\
\hline
\end{tabular}

Source: TAEXP and FDISC were extracted from CBN statistical budgeting (2012), TBEXP was extracted from budget speeches and appropriation Acts (Various years), while BDISC was computed by the Authors.

Table 1 , table 2 and table 3 contained the data for this study. The data which cover a period of fifteen years relate to total federal government budgeted expenditure (TBEXP), total actual expenditure (TAEXP), budget discipline (BDISC) and fiscal discipline (FDISC) (table 1). It will suffice to clarify here that while BDISC was computed as the ratio of budgeted expenditure to actual expenditure, FDISC on the other hand, was taken as the ratio of budget deficit to GDP. In table 2, the data were classified into their pre and post MTEF (Medium Term Expenditure Framework) adoption with seven years observation in each case.

Table 2: Budget Discipline and Fiscal Discipline Before and after the adoption of MTEF

\begin{tabular}{|c|c|c|c|c|c|}
\hline Year & BDB-MTEF & FDB-MTEF & Year & BDA-MTEF & FDA-MTEF \\
\hline $\mathbf{1 9 9 8}$ & 0.755300716 & -4.92497 & 2006 & 0.97813232 & -0.54619 \\
\hline $\mathbf{1 9 9 9}$ & 0.377869873 & -8.92622 & 2007 & 0.826209348 & -0.56753 \\
\hline $\mathbf{2 0 0 0}$ & 0.948195488 & -2.26483 & 2008 & 0.686338458 & -0.19501 \\
\hline $\mathbf{2 0 0 1}$ & 1.000028586 & -4.6782 & 2009 & 0.745464901 & -3.26692 \\
\hline $\mathbf{2 0 0 2}$ & 1.16751146 & -4.36032 & 2010 & 0.846679087 & -3.25264 \\
\hline $\mathbf{2 0 0 3}$ & 0.999974143 & -2.38864 & 2011 & 0.998388067 & -3.09683 \\
\hline $\mathbf{2 0 0 4}$ & 0.890784056 & -1.51258 & 2012 & 1.130720209 & -2.40657 \\
\hline
\end{tabular}

Source: CBN statistical bulletin (2012) and authors' computations

Similarly, table 3 presents five years pre and five years post enactment of the Fiscal Responsibility Act (FRA) with respect to budget discipline and fiscal discipline. It should be noted that FRA was enacted in 2007. Specifically, the data are grouped into budget discipline before FRA (BDB-FRA), and budget discipline after FRA (BDA-FRA), as well as fiscal discipline before FRA (FDBFRA), and fiscal discipline after FRA (FDAFRA). 
Table 3: Budget Discipline and Fiscal Discipline Before and after the enactment of FRA

\begin{tabular}{|l|l|l|l|l|l|}
\hline Year & BDB-FRA & FDB-FRA & Year & BDA-FRA & FDA-FRA \\
\hline $\mathbf{2 0 0 2}$ & 1.167511 & -4.36032 & 2008 & 0.686338 & -0.19501 \\
\hline $\mathbf{2 0 0 3}$ & 0.999974 & -2.38864 & 2009 & 0.745465 & -3.26692 \\
\hline $\mathbf{2 0 0 4}$ & 0.890784 & -1.51258 & 2010 & 0.846679 & -3.25264 \\
\hline $\mathbf{2 0 0 5}$ & 0.977855 & -1.10763 & 2011 & 0.998388 & -3.09683 \\
\hline $\mathbf{2 0 0 6}$ & 0.978132 & -0.54619 & 2012 & 1.13072 & -2.40657 \\
\hline
\end{tabular}

Source: CBN statistical bulletin (2012) and authors' computations

\section{Descriptive Statistics}

Table 4 shows the descriptive statistics of total budgeted expenditure (TBEXP), total actual expenditure (TAEXP), budget discipline (BDISC) and fiscal discipline (FDISC) for a period of fifteen (15) years (1998-2012).

Table 4: Descriptive Statistics of Budgeted Expenditure, Actual Expenditure, Budget discipline and Fiscal Discipline

\begin{tabular}{|l|l|l|l|l|l|}
\hline & $\mathrm{N}$ & Minimum & Maximum & Mean & Std. Deviation \\
\hline & Statistic & Statistic & Statistic & Statistic & Statistic \\
\hline TBEXP & 15 & 358103.50 & 4749000.00 & $\begin{array}{l}1912043.867 \\
3\end{array}$ & 1320710.72078 \\
\hline TAEXP & 15 & 487113.40 & 4233013.33 & $\begin{array}{l}2118460.862 \\
9\end{array}$ & 1321319.16234 \\
\hline BDISC & 15 & .3779 & 1.1675 & .888630 & .1961209 \\
\hline FDISC & 15 & -8.9262 & -.1950 & -2.899671 & 2.2416793 \\
\hline Valid N (listwise) & 15 & \multicolumn{3}{|l}{} & \\
\hline
\end{tabular}

Source: Field Work (2013)

The statistics reveal that the mean total budgeted expenditure (TBEXP) for the period under consideration was about N1.912 trillion, while the minimum and maximum budgeted expenditure were respectively about N358.103 billion and N4.749 trillion with a standard deviation of about N1.3207 trillion. For the same period, the total actual expenditure (TAEXP) has a mean of about N2.118 trillion, minimum of N487.113billion, maximum of N4.233 trillion, and a standard deviation of about N1.3213. It can be observed from table 1 that while the mean and minimum TAEXP are significantly higher than the mean and minimum TBEXP, the maximum TAEXP was less than the maximum TBEXP. The comparison of TBEXP and TAEXP is made clearer in the trend graph shown in figure 2 and figure 3 . Figure 2 shows that in most of the years, the TAEXP bars are higher than the TBEXP bars, indicating higher actual expenditures in relation to the budgeted expenditures. 


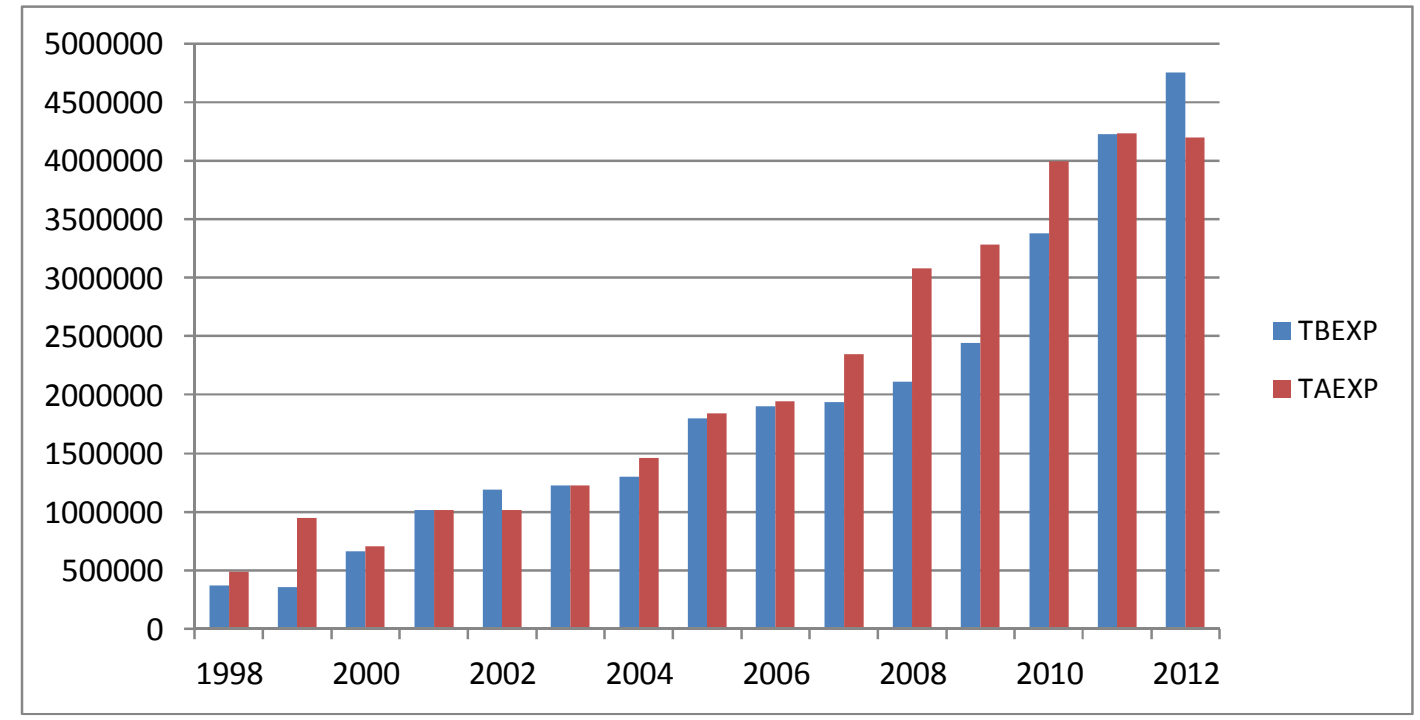

Figure 2: Comparing Budgeted Expenditure and Actual Expenditure

Similarly, figure 3 shows the trend curve of TAEXP almost naturally on the top of the TBEXP curve, indicating that actual expenditure almost always exceeded budget expenditures.

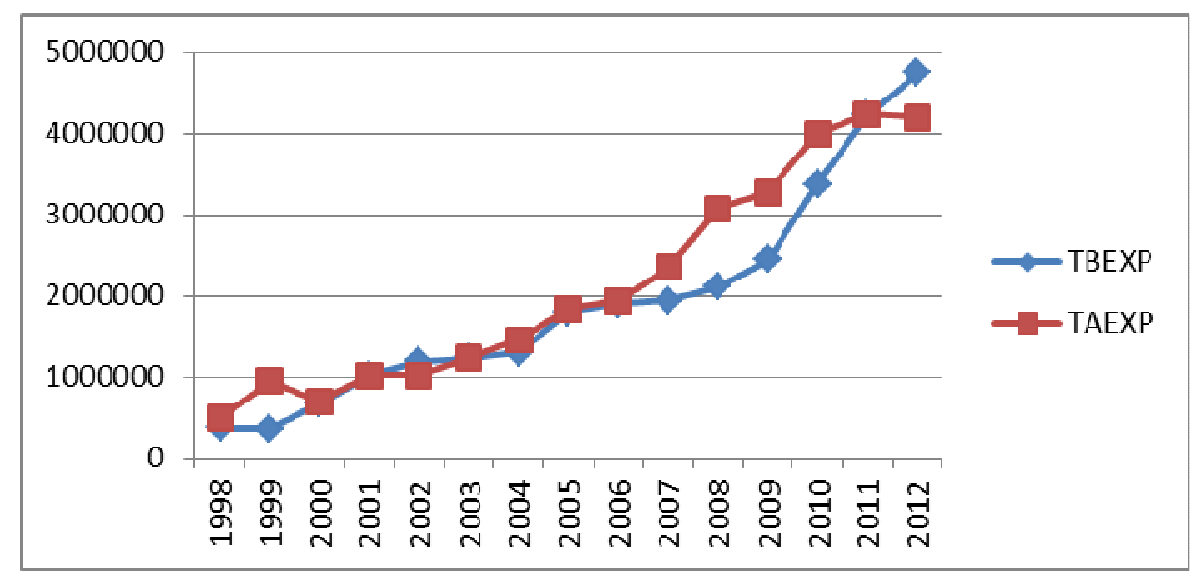

Figure 3: Trend of Budgeted Expenditure and Actual Expenditure (1998-2012)

However, the exception to this expenditure trend was in 2001, 2002 and 2012. In 2001, the coordinates of TAEXP and TBEXP coincided, indicating that what was budgeted was about what was spent, while in 2002 and 2012 the TBEXP overshadowed TAEXP as shown in the figure 3.
Table 4 also revealed some statistics about budget discipline (BDISC) and fiscal discipline (FDISC) for the fifteen years period considered. It shows a mean BDISC of 0.888630, minimum (lowest) of 0.3779, maximum (highest) of 1.1675, and standard deviation of 0.1961209 . Also, the trend of budget discipline depicted in figure 4 further

Ben-Caleb Egbide, Adeyemi Kenneth Sola and Iyoha Francis (2014), Journal of Accounting and Auditing: Research \& Practice, DOI: 10.5171/2014.207739 
explains the statistics in table 4 . The figure reveals that the least discipline was exercised in 1999 while the highest discipline for the period was exercised in 2002.

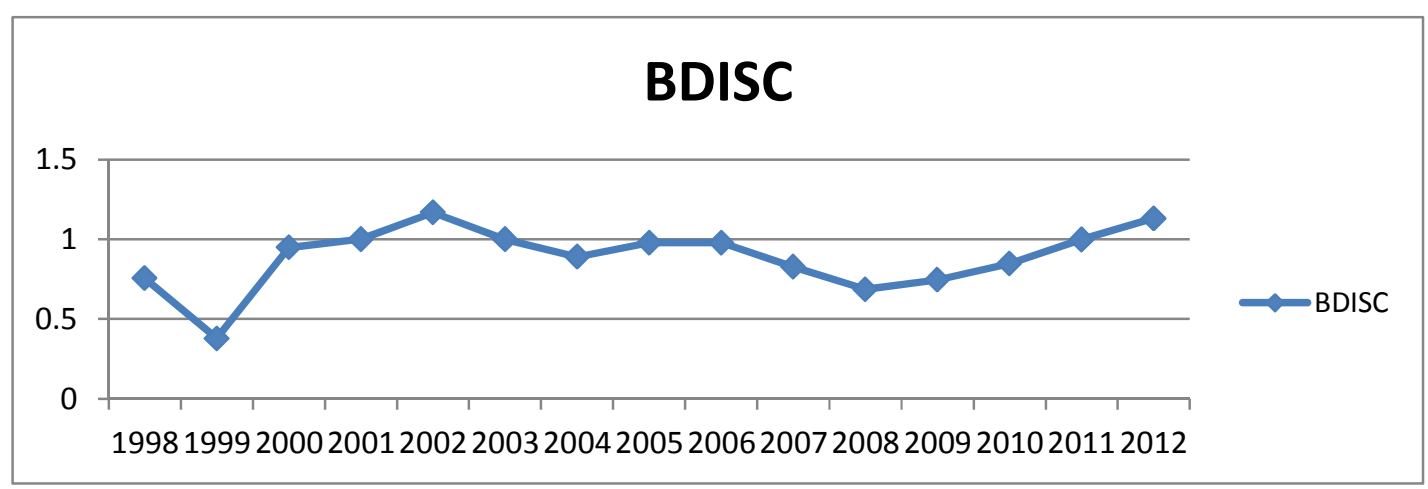

Figure 4: Trend of Budget Discipline (1998-2012)

Another interesting observation to be made from the trend graph is the fact that from 2008 to 2012, there has been a steady increase in the rate of discipline from about 0.686 in 2008 to 1.131 in 2012. Specifically, budget discipline was recorded in only three years (2001, 2002 and 2012) representing $20 \%$ of the years, while indiscipline was evidence in 12 years representing $80 \%$ of the years studied. This is clearly shown in figure 5.

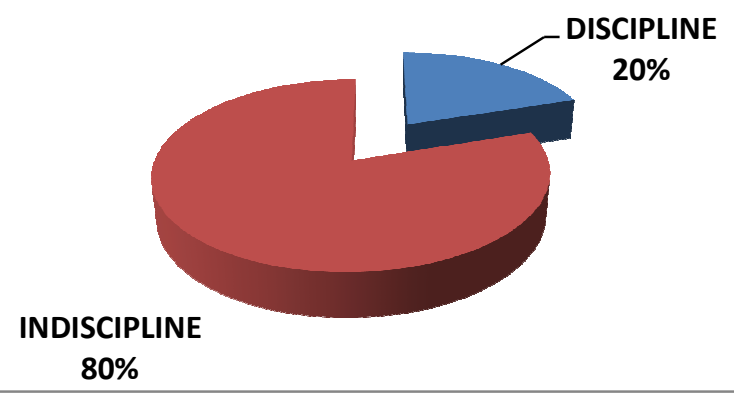

Figure 5: Budget Discipline and Budget Indiscipline (1998/2013)

For fiscal discipline (FDISC), (the ratio of budget deficit to Gross Domestic Product (GDP)), table 4 reveals that the minimum (8.9262), maximum (-0.1950), and mean ($2.899671)$ values are all negative, indicating that for the fifteen years under consideration, fiscal indiscipline had been perpetrated in Nigeria. An inspection of the trend graph in figure 6 makes this clearer. The chart reveals that lowest discipline was recorded in 1999 while the highest form of discipline was evidenced in 2008. It will also be appropriate to observe that since 2009 the rate of fiscal discipline has consistently and marginally been on the increase. This corroborated trend of BDISC also observed from 2008 to 2012. 


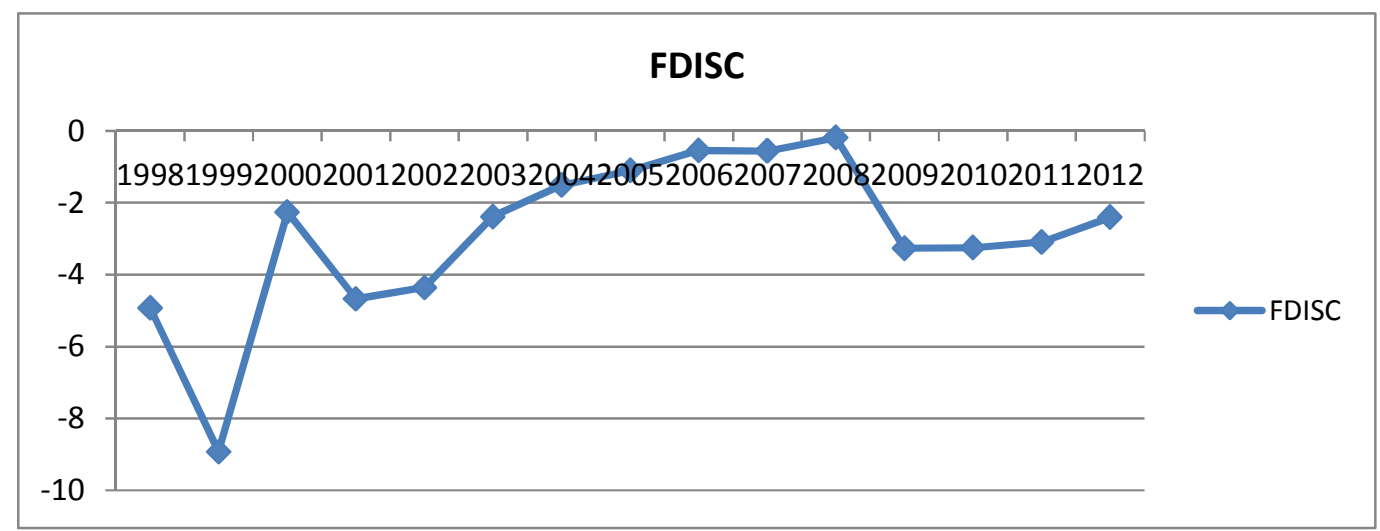

Figure 6: Trend of Fiscal Discipline (1998-2012)

\section{Budget Discipline and Fiscal Discipline before (1998-2004) and after (2006-2012) MTEF}

As already noted in the literature review section of this paper, the Medium Term Expenditure Framework (MTEF) was introduced into the Nigerian budgetary system in 2005. Charting a line graph seven (7) years before and seven (7) years after MTEF reveals very interesting features with respect to budget discipline (figure 7 ' $A$ ') and fiscal discipline (figure 7 ' $B$ '). Figure 7 ' $A$ ', for

'A'

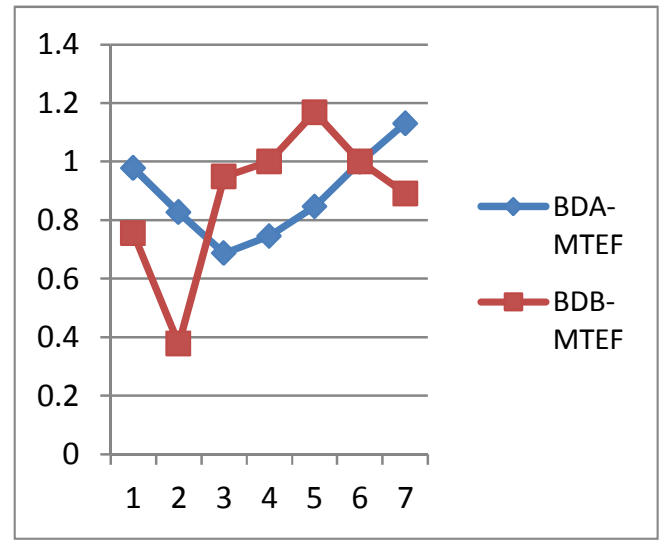

instance, revealed that BDB-MTEF (Budget Discipline Before MTEF) and BDA-MTEF (Budget Discipline After MTEF) are mirror images of each other, with only one point each exceeding one. However, BDB-MTEF appears to be more erratic than BDA-MTEF. Similarly, figure $7(\mathrm{~B})$, the fiscal discipline before the adoption of MTEF (FDB-MTEF), was more irregular and more unpredictable than the fiscal discipline after MTEF (FDAMTEF). However, both FDB-MTEF and FDAMTEF lie below the horizontal axis indicating fiscal indiscipline in all the years considered.

'B'

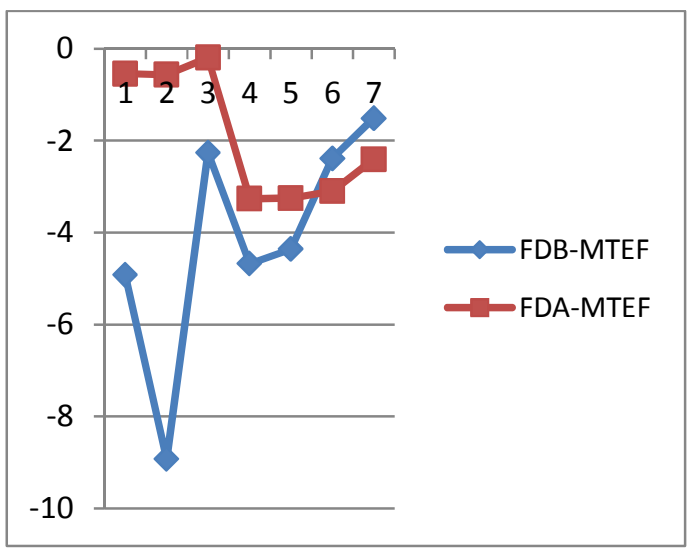

Figure 7: Line graph of Budget Discipline (A) and Fiscal Discipline (B) before and after MTEF

Ben-Caleb Egbide, Adeyemi Kenneth Sola and Iyoha Francis (2014), Journal of Accounting and Auditing: Research \& Practice, DOI: 10.5171/2014.207739 


\section{Budget Discipline and Fiscal Discipline before (2002-2006) and after (2008-2012) FRA}

The Fiscal Responsibility Act (FRA) was passed into law in 2007 as also noted in literature. So, five years pre-FRA corresponds to 2002-2006, while five years post-FRA corresponds to 2008-2012. Figure 8 (A) reveals that the trend of budget discipline after the FRA (BDA-FRA) is more predictable, and it was five years before FRA (BDB-FRA). This is observable from the trend line of BDA-FRA which is almost a straight line sloping upwards from left to right.

A

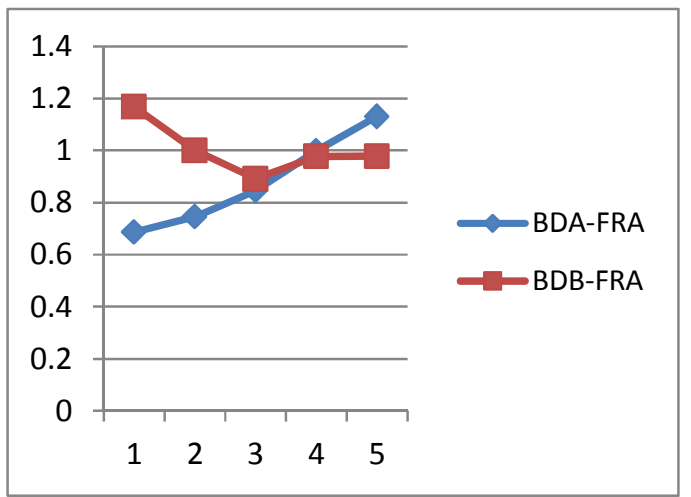

Figure 8(B) however, presents an opposite trend. In this case, there was consistent increase in fiscal discipline five years before the enactment of FRA from a record low value of -4.360 in 2002 to -0.546 in 2006 , while FDA-FRA depicted more erratic trend from -0.195 in 2008 plummeted to -3.2669 in 2009, before beginning to increase consistently but marginally up to 2012 . Again, the trend of budget/fiscal discipline from 2009 to 2012 is commendable, and should be encouraged as good portents for the Nigerian budgetary operations, as well as Nigeria's economy.

B

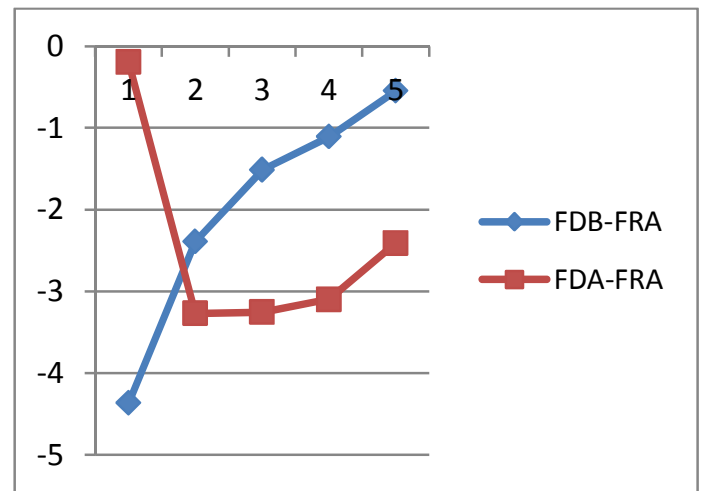

Figure 8: Trend of Budget Discipline (A) and Fiscal Discipline (B) before and after FRA

\section{Testing for Normality and Outliers}

The Kolmogorov-Smirnov test was used for normality, while the box-plot was used to test for outliers. The normality test result shown on table 5 reveals that the two variables used in this study namely; BDISC and FDISC did not violate the normality assumptions, since their K-S coefficients have sig. values greater than the 0.05 benchmark.

Table 5: Tests of Normality

\begin{tabular}{|l|l|l|l|}
\hline & \multicolumn{4}{|l|}{ Kolmogorov-Smirnov(a) } \\
\hline & Statistic & Df & Sig. \\
\hline BDISC & .153 & 15 & $.200\left(^{*}\right)$ \\
\hline FDISC & .168 & 15 & $.200\left(^{*}\right)$ \\
\hline
\end{tabular}

* This is a lower bound of the true significance.

A Lilliefors Significance Correction.

Source: Field Work (2013)

Ben-Caleb Egbide, Adeyemi Kenneth Sola and Iyoha Francis (2014), Journal of Accounting and Auditing: Research \& Practice, DOI: 10.5171/2014.207739 
In testing for outliers, the box plots technique was employed. Figure 9 shows the box plots for BDISC (A) and FDISC (B). The result revealed that one outlier in each case with ID numbers 2 and 2 representing 0.3779 for
BDISC, and -8.9262 for FDISC respectively. The absence of apteryx on the outliers indicate that the outliers do not have strong influence on the data set, and as such will not significantly distort the result of the analyses

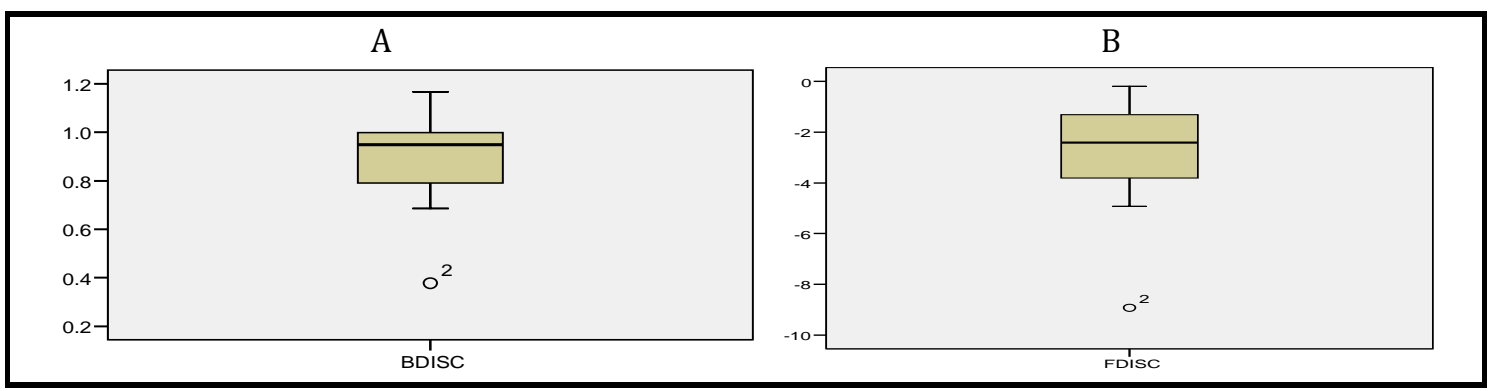

Figure 9: Box Plot Test for Outliers in BDISC (A) and FDISC (B)

\section{The Paired Sample T-Test}

The paired sample T-test (pre-test/post-test design) was employed to measure the impact of Medium Term Expenditure Framework (MTEF), and Fiscal Responsibility Act (FRA) on Budget Discipline (BDISC), and Fiscal Discipline (FDISC) in Nigeria. With respect to MTEF, data for seven (7) years before its adoption (1998-2004), and seven (7) years after its adoption (2006-2012) were used in the analysis. The result in table 7 revealed a $\mathrm{t}$-value of -0.091 (sig. $=0.931$ ) for pair 1 (BDB-MTEF/BDA-MTEF), and a t-value of 1.841 (sig. = 0.115) for pair 2 (FDBMTEF/FDA-MTEF). These results indicate that there is no statistically significant difference in budget discipline (BDISC), and fiscal discipline (FDISC) seven years before and seven years after the adoption of MTEF in Nigeria. The result favours the proposition that MTEF had not significantly impacted on the quality of budget management in Nigeria. However, the mean budget discipline increased marginally in absolute terms from 0.877095 (pre-MTEF) to 0.887419 (post MTEF), implying that MTEF have had some practical impact on budget discipline, but the change is not large enough to be considered as been statistically significant. The mean of fiscal discipline also demonstrated an increase in absolute terms from -4.150820 (pre-MTEF) to -1.002851 (post-MTEF). But like in budget discipline, the increase was not large enough to be statistically significant.

Similarly, with respect to Fiscal Responsibility Act (FRA) enacted in 2007, the result indicates no statistically significant difference in budget discipline and fiscal discipline, five years before and five years after the enactment of FRA in Nigeria. In other words, the enactment of Fiscal Responsibility Act 2007 had not influenced the quality of budget management in Nigeria in any significant way in support of the null hypothesis of this study. This is evidenced in the t-statistics, and their associated significance values of 1.089 (sig. = 0.337), and 0.393 (sig. $=0.715$ ), for pair 3 (BDBFRA/BDA-FRA), and pair 4 (FDB-FRA/FDAFRA) respectively. 
Table 6: Paired Sample T-Test Result

\begin{tabular}{|c|c|c|c|c|c|}
\hline Pair & Variable & $\begin{array}{c}\text { Nos of } \\
\text { Observation }\end{array}$ & Mean & t-statistics & $\begin{array}{l}\text { Sig (2- } \\
\text { tailed) }\end{array}$ \\
\hline \multirow{3}{*}{1} & BDB-MTEF-BDA-MTEF & 7 & -0.0103240 & \multirow[t]{3}{*}{-0.091} & \multirow[t]{3}{*}{0.931} \\
\hline & BDB-MTEF & 7 & 0.877095 & & \\
\hline & BDA-MTEF & 7 & 0.887419 & & \\
\hline \multirow{3}{*}{2} & FDB-MTEF-FDA-MTEF & 7 & -2.2462933 & \multirow[t]{3}{*}{-1.841} & \multirow[t]{3}{*}{0.115} \\
\hline & FDB-MTEF & 7 & -4.150820 & & \\
\hline & FDA-MTEF & 7 & -1.904527 & & \\
\hline \multirow{3}{*}{3} & BDB-FRA-BDA-FRA & 5 & 0.1213333 & \multirow[t]{3}{*}{1.089} & \multirow[t]{3}{*}{0.337} \\
\hline & BDB-FRA & 5 & 1.002851 & & \\
\hline & BDA-FRA & 5 & 0.881518 & & \\
\hline \multirow{3}{*}{4} & FDB-FRA-FDA-FRA & 5 & 0.4605239 & \multirow[t]{3}{*}{0.393} & \multirow[t]{3}{*}{0.715} \\
\hline & FDB-FRA & 5 & -1.983070 & & \\
\hline & FDA-FRA & 5 & -2.443594 & & \\
\hline
\end{tabular}

Source: Field Work (2013)

These results negate the expectations of economic managers and proponents of MTEF who had believed that MTEF is the key to achieving budget/fiscal discipline, and better operating efficiencies over the medium term. It is, however, in consonance with the testimony of Nussle (2012) that "the budget process chosen is less important than the political leadership provided"; or that it is not the tools, but the craftsman that makes the difference in the outcome. Going by this testimony, it can be inferred that budgetary reforms will be effective and impact the quality of budget, to the extent that the political leaders allow. It also tallies with the view that good governance and good budgeting are intertwined. In other words, the quality of a government can be x-rayed from the quality of its budgetary management (Ben-Caleb \& Agbude, 2012). After all, the major attributes of good budgeting namely; effectiveness, efficiency, transparency, accountability and discipline are also ingredients of good governance, which if demonstrated, can engender value to the nation and the people (United Nations, 2007; Kaufman and Kraay, 2008).

\section{Conclusion and Recommendations}

This paper was fixated on the empirical evaluation of the impact of budgetary reforms especially MTEF, and FRA on the quality of budget management in Nigeria. Utilising both descriptive and inferential analyses, the paper achieved its aim; hence, we conclude that budget reforms had not had any significant influence on the Nigerian budget management. In other words, the MTEF and FRA had not been able to tame the spate of indiscipline in Nigeria's budgetary process. However, it is necessary to state that the reforms themselves are not as much a problem than the "will" to enforce and implement the reforms. This is in tandem with the observation that most policies rolled out in developing nations, including Nigeria, do not achieve their desired result (Makinde, 2005). It is this policy 'expectation gap' that constitutes the real problem in Nigeria.

Therefore, in order to bridge the gap between policy intentions and their actual achievement, and allow the impact of reforms to be visible in Nigeria, the following recommendations are made: first, there should be a deliberate effort to imbibe the culture of discipline among all the responsibility officers in government. This 
will eschew the iniquitous impact of indiscipline on the economy. Secondly, the Appropriation Act (budget) like all other Acts of the National Assembly should be accorded the same legal weight. This will imply that the violation of the budget rules should be appropriately sanctioned. Thirdly, the government should provide the leadership and political will to enforce the provisions of FRA, MTEF and all other public sector reforms. Also, proper monitoring of expenditure will go a long way to discourage opportunistic behaviours, as well as other innovative ways of short circuiting or circumventing expenditure control as well as corruption

\section{Reference}

1. Aruwa, S A. (2004) 'Nigerian Budgeting Process and the Magnitude of Budget Variances', The Academy Journal of Defence Studies, 13(3), 12-35.

2. Ben-Caleb, E and Agbude, GA. (2012), 'Good Budgeting and Good Governance: A Comparative Discourse', The Public Administration and Social Policies Review 2(9), 49-59.

3. Ben-Caleb, E and Agbude, GA. (2013), 'Budget Discipline in Nigeria: A Critical Evaluation of Military and Civilian Regimes', Economica, 9(1), 91-101.

4. Bengali, K., (2004), 'Budgeting for Poverty Reduction', A Background Paper presented as a part of the Pakistan Legislative Strengthening Consortium (PLSC); Pakistan Institute of Legislative Development and Transparency (PILDAT). (Retrieved April 3, 2012), http://www.millat.com/democracy/Budget/ Background_paper_Poverty.pdf

5. Brumby, J (1998), Chapter 16: Budgeting reforms in OECD member Countries (Online). (Retrieved July 18, 2013), http://www.internationalbudget.org/wpcontent/uploads/Budgeting-Reforms-inOECD-Member-Countries.pdf
6. Garba, A.G. (2011), 'The Institutional Framework for Budgeting in Nigeria: Implications, Limitations and Required Actions by Government, Citizens and the NES' Paper Presented at the NES Budget Seminar, $31^{\text {st }}$ May 201, CIBN Building, VI, LAGOS.

7. Government Finance Officers Association (GFOA) (1999), Recommended Budget Practices: A Framework for Improved State and Local Government Budgeting' (Online), (Retrieved April 11, 2012), http://www.gfoa.org/services/dfl/budget/R ecommendedBudgetPractices.pdf

8. Government Integrated Financial Management Information System (GIFMIS) (2011), 'Budgeting and Budget Management Reforms' (Online), (Retrieved September 20, 2013), http://www.gifmis.gov.ng/gifmis/index.php?option=com_content $\& v i e w=a$ rticle\&id=6\&Itemid $=6 \# 1$

9. Kaufman, D. and Kraay, A. (2008), 'Governance Indicators: Where Are We, Where Should We Be Going?' Policy Research Working Paper No.4370 of the World Bank. (Retrieved September 21, 2013), http://info.worldbank.org/governance/wgi/ pdf/wps4370.pdf

10. Lienert, I. and Sarraf, F. (2001), 'Systemic Weaknesses of Budget management in Anglophone Africa. International Monetary Fund's Working Paper No WP/01/211.

11. Lucien, P (2002), 'Sound Budget Execution for Poverty Reduction' World Bank Institute (Online), (Retrieved on November 12 2011)

http://citeseerx.ist.psu.edu/viewdoc/downl oad?doi=10.1.1.201.4005\&rep=rep1\&type $=p$ $\mathrm{df}$

12. Makinde, T. (2005) 'Problems of Policy Implementation in Developing Nations: The Nigeria Experience' Journal of Social Sciences, 11(1) 63-69.

13. National Democratic Institution (NDI) (2003), 'The Legislature and the Budget 
Process: An International Survey' (Online), (Retrieved November 15, 2011), http://www.ndi.org/files/1651_gov_budget_ 093103.pdf

14. Nussle, J. (2012) 'Perspectives on Budget Process Reform', Journal of Public Budgeting \& Finance, 32(3), 57-60.

15. Obasanjo, O. (1999), '2000 Budget Speech: People's Budget, presented by His Excellency President Olusegun Obasanjo at the Joint Session of the National Assembly. Abuja, November 24, 1999.

16. Olomola, A.S. (2009) 'Strategies and Consequences of Budgetary Reforms in Nigeria' Paper for Presentation at the 65th Annual Congress of the Institute of International Public Finance (IIPF), Cape Town, South Africa.

17. Omolehinwa, E.O. and Naiyeju, J.K. (2011) Theory and Practice of Government Accounting in Nigeria, Pumark Nigeria Limited, Lagos.

18. Otokiti, S.O. (2010) Contemporary Issues and Controversy in Research Methodology, Management Review Limited, Lagos

19. Pallant, J. (2011) SPSS Survival Manual: A Step by Step Guide to Data Analysis Using SPSS, Allen \& Unwin, Australia
20. Pascua, L. (2005), 'Operationalizing the MTEF in the Philippines: A Key to Reducing Poverty, Defining an Agenda for Poverty Reduction' Proceedings of the first Asian and Pacific Forum in Poverty. Volume 1 pp. 138144

21. State Partnership for Accountability, Responsiveness and Capability (SPARC), (2009), "Scoping the Introduction of Medium term Expenditure Framework in Nigeria State Government. (Online), (Retrieved September 21, 2013), http://www.sparcnigeria.com/RC/files/2.1.6_MTEF_Scoping_R eport_Discussion_Draft_26_Sept_2009.pdf

22. United Nations (2007), 'Good Governance practices for the Protection of Human Rights' (Online) (Retrieved on August 15, 2013), http://www.ohchr.org/Documents/Publicati ons/GoodGovernance.pdf

23. World Bank (2001), 'Honduras Public Expenditure Management for Poverty Reduction and Fiscal Sustainability: Latin America and the Caribbean Region' Poverty Reduction and economic Sector Management Unit. Report No. 22070 (Retrieved on September 21, 2013), http://wwwwds.worldbank.org/external/default/WDSCo ntentServer/WDSP/IB/2001/08/29/000094 946_0108070401001/Rendered/PDF/multi 0page.pdf. 